\title{
JOHN LOCKE E A DIVERSIDADE DE INTERPRETAÇÕES
}

\author{
JOHN LOCKE AND THE DIVERSITY OF INTERPRETATIONS
}

Antônio Carlos Santos*

\section{RESUMO:}

O objetivo deste texto é apresentar, por um lado, os eixos centrais da chamada "Escola de Cambridge" e, por outro, analisar os procedimentos metodológicos e chaves de leituras dos comentadores clássicos de Locke vinculados a essa mesma escola. Para cumprir esse objetivo, o artigo é composto de duas partes: na primeira, serão problematizados os pontos essenciais da "Escola de Cambridge", notadamente os defendidos por Skinner, assim como as críticas mais contundentes sobre sua abordagem; na segunda, serão analisadas as principais interpretações e leituras de Locke relacionadas à mesma "Escola" e que deram o tom da leitura de seu pensamento na segunda metade do século XX. No fundo, as duas partes conectam-se porque os fundadores da "Escola" inglesa, quase todos, foram pesquisadores da obra de Locke. Com isso, espera-se que este texto possa contribuir para minimizar a lacuna bibliográfica sobre os estudos de Locke no Brasil e que inspire novas pesquisas e abordagens, seja sobre o pensador inglês, seja na área da Filosofia política.

PALAVRAS CHAVE: John Locke. Escola de Cambridge. Procedimentos metodológicos. Skinner. Filosofia política.

\section{ABSTRACT:}

The purpose of this text is to present, on the one hand, the central axes of the so-called "Cambridge School" and, on the other hand, to analyze the methodological and key procedures of reading of the classic commentators of Locke, linked to that same school. In order to fulfill this objective, it contains two parts: in the first one, the essential points of the "Cambridge School" will be problematized, notably those defended by Skinner, as well as the most striking critiques about his approach; In the second, we will analyze the main interpretations and readings of Locke linked to the same "School" and that gave the tone of the reading of his thought in the second half of the twentieth century. In the background, the two parts connect because the founders of the "School" almost all were researchers of Locke's work. Thus, it is hoped that this text can contribute to minimize the bibliographical gap on Locke's studies in Brazil and to inspire new researches and approaches on the English thinker or in the area of Political Philosophy.

KEY WORDS: John Locke. Cambridge School. Methodological procedures. Skinner. Political Philosophy.

\footnotetext{
* Professor de Ética e Filosofia Política da Universidade Federal de Sergipe (UFS). Pesquisador Bolsista Produtividade do CNPQ. E-mail: acsantos12@uol.com.br. Este artigo faz parte de uma pesquisa maior, ainda em andamento, que versa sobre John Locke, subvencionada pela Bolsa Produtividade do CNPQ.
} 
Nas ciências do espírito o interesse do investigador que se volta para a tradição é motivado, de uma maneira muito especial, pelo respectivo presente e seus interesses. É só pela motivação do questionamento que se estabelece o tema e o objeto da investigação. (GADAMER, 2004, p. 377-378).

No Brasil, o debate sobre a questão metodológica em Filosofia e, de modo particular, em Filosofia Política, é bastante reduzido. Há, em princípio, uma espécie de pressuposto básico, o de que esse problema é irrelevante a tal ponto que é deixado para segundo plano e só vem à tona quando as agências de fomento, em sua avaliação para a concessão de bolsas, exigem, como tópico específico, o método e os procedimentos metodológicos do projeto de pesquisa, muito mais por associação às outras áreas do conhecimento, do que pela especificidade própria à filosofia. Quem avalia projeto de pesquisa sabe que não é raro encontrar confusões entre método e técnicas de pesquisa, entre procedimentos metodológicos e questões próprias e obrigatórias a toda a pesquisa, como leitura e fichamento de texto. Além disso, tem-se a ilusão de que o aluno que chega à formação stricto sensu já esteja sabendo filosofar o suficiente, de tal modo que pouco se discute essa questão na pós-graduação.

Ora, se é verdade que cabe à Filosofia Política o esforço analítico e argumentativo, visando a precisar e compreender o uso e o sentido dos principais conceitos que estão na interface da política, não seria importante a descrição de qual melhor caminho seguir? Como tratar temas que estão no limite, entre a Teoria Política e a Filosofia Política, sem a delimitação de um método mais ou menos seguro de análise? Tão importante quanto a pesquisa, não seria a descoberta dos meios necessários para os fins almejados? Que método seguir na área específica da Filosofia Política? Quais os procedimentos metodológicos mais adequados? Deve-se privilegiar abordagens históricas do texto, empregando métodos e práticas de historiadores, ou tomar um viés mais filosófico no sentido stricto do termo, com vistas a avaliar a força dos argumentos e temas universais? ${ }^{1}$.

O fato é que a preocupação metodológica em Filosofia Política começou em meados do século passado e pautou as leituras da área, especialmente as que dizem respeito a John Locke. Longe de exaurir esse tema tão delicado quanto complexo, este texto pretende apresentar, por um lado, os eixos centrais da chamada "Escola de Cambridge", pioneira nesse tipo de análise em meados do século $\mathrm{XX}$ e, por outro, analisar os procedimentos metodológicos e chaves de leituras dos comentadores clássicos de Locke vinculados a essa

\footnotetext{
${ }^{1}$ Sobre estas questões, ver Bobbio (2000, p. 95), Strauss (1984, p. XV) e Bloom (s. d., p. 205s). Ver ainda Spitz (2014, p. 347).
} 
mesma "Escola". No fundo, o objetivo último deste texto é analisar os elementos mais adequados para ler o pensamento político de Locke no mundo contemporâneo. Isso porque, como já é sabido, o estudo de textos clássicos é um recurso imprescindível à compreensão do passado com as ferramentas do mundo atual e, inclusive, em vista dos problemas da atualidade.

Assim, para cumprir esse objetivo, o presente texto contém duas partes: na primeira, serão problematizados os pontos essenciais da "Escola de Cambridge", notadamente os defendidos por Skinner, seu principal expoente e defensor, assim como as críticas mais contundentes à sua abordagem; na segunda, serão analisadas as principais interpretações e leituras de Locke vinculadas à mesma "Escola" e que deram o tom da leitura de seu pensamento na segunda metade do século XX. Na primeira parte, considera-se que a "Escola", construindo, ao longo dos anos, seu corpus à medida que combatiam suas críticas, se modificou um pouco nos últimos trinta anos de sua existência. Por conseguinte, um núcleo de pressupostos resistiu ao tempo, e é esse núcleo que este texto focaliza. Na segunda parte, considera as leituras ou interpretações sobre Locke: elas visam apresentar um quadro interpretativo de como Locke foi lido ou apropriado diferentemente, segundo certas chaves de leitura. No fundo, as duas partes do texto se conectam, porque os fundadores da "Escola" inglesa, quase todos, foram pesquisadores de Locke, como já foi ressaltado acima. Com isso, espera-se que esta forma de trabalho possa contribuir para minimizar a lacuna bibliográfica sobre Locke no Brasil e inspirar novas pesquisas e abordagens seja sobre o pensador inglês, seja na área da Filosofia Política.

O debate em torno do que, na atualidade, é conhecido como "Escola de Cambridge" começou em 1956, quando Laslett ${ }^{2}$ declarou, com evidente intenção de polemizar, que "no momento, [...] a filosofia política está morta" (LASLETT, 1956, p. VII). Essa sentença surgiu como uma bomba no meio acadêmico do período, porque estava vinculada a um contexto de questionamentos a antigas práticas no tratamento filosófico das ideias políticas. A

\footnotetext{
${ }^{2}$ Sobre o assunto, conferir Laslett (1949) e Laslett (1960, tradução em português de 2001). É verdade que o argumento de maior consistência, sobre as circunstâncias da produção do texto de Locke, se fragiliza à medida que o próprio Locke destruiu boa parte dos traços da produção de sua obra. Após a prisão de Shaftesbury, Locke passou a ser vigiado e, com a morte de Sydney, acusado de participar do debate político na época, sendo morto pouco tempo depois, Locke decidiu queimar parte de seus manuscritos e fugir para Amsterdam. Sobre este debate, ver Locke (2008) e Cranston (1957).
} 
provocação de Laslett visava também forjar uma nova concepção de pesquisa histórica, frente aos iminentes desafios da Filosofia da Linguagem e às abordagens sociológicas da política, dando assim um tom histórico, a fim de aproximar-se o mais fielmente possível do autor. Por essa razão, afirma Laslett em sua apresentação à edição crítica dos Dois tratados sobre o governo: "Nosso primeiro propósito deve ser um modesto exercício de historiador estabelecer os textos de Locke como ele gostaria que fossem lidos, fixá-los em seu contexto histórico, no próprio contexto de Locke" (LASLETT, 1960, p. 4). Essa tarefa foi de tal modo tão bem-sucedida que Laslett rompeu com a tradição de leitura do pensamento político de Locke que remontava ao século XVIII. Ora, como se lia, até então, o Segundo tratado sobre o governo? A partir da ideia de que o texto de Locke teria sido escrito para legitimar a queda de Jaime II e fundamentar a ascensão de Guilherme de Orange. Essa antiga ideia era tão evidente que, até o retorno de Locke, do exílio em Amsterdam, para a Inglaterra, no navio do próprio Guilherme de Orange, dava ares de retorno triunfal à Revolução Gloriosa, o que justificaria a conexão entre os dois. As pesquisas de Laslett demonstraram que a obra de Locke foi escrita bem antes da mencionada revolução. Por conseguinte, a conexão, aparentemente tida como necessária, não procederia do ponto de vista histórico, não seria ela o contexto da escrita do texto. Essa mudança na abordagem do objeto de estudo pautou o início do que seria chamado "Escola de Cambridge".

Embora o debate tenha começado no final dos anos 50 do século passado, foi ao longo da década seguinte que os historiadores de Cambridge ganharam notoriedade, originando uma escola de leitura graças à publicação de uma sequência de obras mais ou menos no mesmo período com o mesmo foco de análise: Pocock, em 1962, que reivindicou uma história do pensamento político no domínio filosófico dos textos clássicos; Skinner, em 1966, que defendeu o contextualismo linguístico no campo das pesquisas históricas e provocou um enorme debate, ainda aberto, sobre a teoria e método na História Política, envolvendo várias disciplinas das Humanidades; e Dunn que, em 1968, defendeu sua tese sobre Locke, tomando como referencial metodológico os colegas da mesma escola. O fato de esses autores terem uma forma mais ou menos específica de ler o texto clássico não significa dizer que não haja diferenças, nuanças, detalhes, ênfases distintas entre eles. Skinner, por exemplo, insiste na necessidade da recuperação da intenção do autor, enquanto Pocock está preocupado com os chamados paradigmas e discursos linguísticos que caracterizam o texto do autor clássico. Não obstante as diferenças entre eles, num ponto eles se convergem: a ideia de que a Filosofia Política é anacrônica e desprovida de sentido, razão pela qual o peso da análise nas pesquisas 
deve ser dado à história no seu contexto linguístico. Na perspectiva desse grupo, a pesquisa toma como ponto de partida as condições de vida do autor, os sistemas linguístico, econômico, social e religioso nos quais ele está inserido, isso porque, de uma forma ou de outra, esses aspectos são determinantes para o pensamento do autor em sua obra. $\mathrm{O}$ argumento central de Skinner é o de que todo autor está inserido num universo de convenções linguísticas que são parte do próprio texto, razão pela qual essas convenções devem ser o foco da análise.

O ponto de partida de Skinner é perguntar sobre os procedimentos necessários para a compreensão de um texto (SKINNER, 1996, p. 3). A essa pergunta, segundo ele, há duas escolas metodológicas distintas: uma que dá relevo ao texto e outra, ao contexto. Skinner critica ora uma ora outra, dadas suas insuficiências e limitações, e prepara o terreno para a sua própria forma metodológica de análise. Para ele, a leitura pelo contexto histórico crê determinar a forma de leitura pelos contextos econômico, político, social e religioso da obra; e a do texto insiste na autonomia do próprio texto em relação ao contexto, como se ele, o texto, (e só ele) pudesse fornecer todos os dados necessários à sua compreensão. Segundo o historiador inglês, a leitura apenas do texto conduz o leitor a equívocos e anacronismos injustificáveis, à medida que exclui o texto do seu entorno, e a leitura historicamente contextualizada conduz o leitor a escolher determinados pensadores, a reboque de tantos outros, como se apenas uns poucos privilegiados pudessem fazer a história. Skinner, que parte do texto, mas não se prende a ele, defende o contexto linguístico como ponto central de sua metodologia.

Assim, o historiador inglês se manifesta em seu texto inaugural: é preciso “[...] reconhecer na verdade que nossas ideias constituem uma resposta para circunstâncias imediatas, e que nós deveríamos, em consequência, estudar não o texto em si, mas de preferência o contexto de outros acontecimentos que os explicam" (SKINNER, 1969, p. 39). Essa mesma perspectiva foi reafirmada anos depois: "Quando tentamos situar [...] um texto em seu contexto adequado, não nos limitamos a fornecer 'um quadro' histórico para nossa interpretação: ingressamos já no próprio ato de interpretar” (SKINNER, 1996, p. 13). Segundo ele, a compreensão do pensamento político de um autor clássico exige o conhecimento do vocabulário normativo do período histórico em que esse autor se insere, das tensões sociais, políticas e religiosas de então, como também dos elementos próprios à construção do texto em perspectiva. Enfim, não se podem desconsiderar os eventos e os debates sobre questões políticas ocorridas no período histórico em perspectiva. Munido da 
conjuntura na qual a obra foi escrita, dos laços, interesses, filiações e engajamentos políticos de seu autor, o historiador vai questionar: 1) O que tais ideias significavam na época em que foram concebidas? 2) Por que e como foram concebidas? 3) De que forma foram utilizadas e mobilizadas para a sua difusão? 4) Que tipo de resultados se pretendeu atingir? 5) Quais foram os instrumentos ou ferramentas necessárias para a sua divulgação? ${ }^{3}$. Essas questões podem fornecer as conexões necessárias das ideias políticas de autor com o mundo histórico em que foi gerada a obra. Isso porque, para Skinner, o texto por si só não pode ser uma fonte segura: "a análise do contexto que abarca uma obra específica faz parte de um círculo hermenêutico muito mais vasto que a simples exegese do texto" (SKINNER, 1988, p. 104).

Para Skinner, na busca pelos elementos atemporais da Filosofia Política, os pesquisadores valem-se de seus preconceitos, o que, por conseguinte, os deixa vinculados ao contexto em que eles próprios se inserem. Para esse autor, não existe nenhum ponto comum entre textos que pertencem a contextos distintos. Dessa associação duvidosa, ainda segundo ele, nascem quatro tipos de erros que ele denomina de "mitos": o da doutrina, da coerência, da prolepse e do espírito de paroquianismo (SKINNER, 1969, p. 6).

O primeiro erro, segundo Skinner, é o de o comentador achar que todo autor clássico tem uma doutrina, a partir da qual, cada tema constitutivo se vincula necessariamente ao seu objeto de pesquisa. Esse enquadramento se impõe porque os enunciados dos autores estão dispersos no tempo e no espaço e são forçosa e sistematicamente encaixados no esquema mental do intérprete. Assim, temas acidentais são lidos segundo a lógica do comentador, atribuindo-se ao autor estudado aspectos estranhos ao seu pensamento. Ele dá o exemplo de que, segundo essa ideia, haveria em Marcílio de Pádua uma doutrina da separação dos poderes, o que é, para ele, descabido. Para o historiador inglês, pode-se entender o pensamento de Marcílio de Pádua pelo seu contexto, porque esse contexto fornece os elementos necessários para a aparição de tal doutrina (SKINNER, 1996, p. 8).

O fato é que, para Skinner, os adeptos da leitura pelo texto atribuem certas doutrinas aos autores clássicos com o objetivo de obter legitimidade para suas próprias opiniões, por vezes, preconceituosas. Isso significa dizer que as análises, mesmo as que tomam como ponto de partida o texto em si, não estão imunes a preconceitos da parte daqueles que o comentam.

\footnotetext{
${ }^{3}$ Dunn (1992, p. 16) afirma: "No estudo da história da teoria política, convém distinguir três tipos de questões: inicialmente, qual é o tema exato desta história que o passado nos transmitiu? De fato, de qual história da teoria política é a história? Em seguida: [...] qual é o melhor modo de compreender esta história, o melhor método para estudá-la? Qual é a melhor perspectiva? E enfim: num nível mais elevado, qual significação intelectual e humana esta história contorna? Por que ela tem tão pouca importância aos olhos de um indivíduo que não tem necessidade de ser ou mesmo de falar com facilidade e precisão a um examinador que deseja acariciar?"
} 
Para Skinner, isso ocorre porque por trás da leitura do texto há um pressuposto, uma certeza que justificaria a interpretação. Nesse tipo de análise, o pesquisador busca elementos distantes da história, como uma espécie de sabedoria atemporal ou mesmo universal capaz de fornecer coerência a sua doutrina e proteção contra tudo que não esteja no próprio texto.

O mito da coerência de um autor é o segundo erro dos comentadores que se atêm ao texto. Segundo Skinner, há pesquisadores que pressupõem que o pensamento dos autores clássicos é coerente e o seu trabalho consiste em encontrar a coerência por trás de supostas incoerências. Evidentemente, todo pesquisador deve estar atento às inconsistências do autor em questão, mas existe sempre o perigo de o leitor achar uma incoerência aparente, quando se trata de uma realidade. Essa visão leva o leitor a crer que o intérprete construiu um sistema intelectual fechado, sem brechas, impedindo o leitor de perceber suas contradições, suas mudanças de concepção a respeito de certos temas e, até mesmo, sua riqueza de pensamento.

O mito da prolepse é o terceiro erro dos adeptos desse tipo de leitura. Trata-se de uma confusão entre o significado do enunciado do historiador com o do autor. Há uma atenção destacada dada ao autor como "pai fundador", ou a uma ideologia, mesmo que isso o autor nunca tenha pretendido ser. Skinner dá especial atenção às pretensões do comentador.

Por fim, o mito do espírito paroquianismo. Diz respeito ao tipo de historiador que reinterpreta o argumento do autor clássico e redescobre relações entre certos textos que, no fundo, não existem. Nesse sentido, aborda a "influência" de um autor sobre o outro, interpreta passagens como se elas estivessem respondendo a outros autores, ignorando sutilezas, nuanças, detalhes etc. Isso significa dizer que esse erro é uma forma de relacionar autores de épocas distintas, apontando elementos supostamente comuns entre elas, cujas características são claramente diferentes.

Enquanto a leitura textual traz os erros acima, a do contexto histórico provoca o chamado determinismo causal e a presunção de que "as ideias de um dado texto devem ser compreendidas em termos de seu contexto social" (SKINNER, 1969, p. 43). Ora, leituras desse tipo conduzem o leitor a uma visão deturpada de que o papel das ideias na sociedade e na política é desprovido de autonomia e de eficácia, porque as ideias são determinadas pelo contexto histórico.

Seria possível fugir desses erros? Como não cair em alguma dessas armadilhas, algumas feitas pelos próprios comentadores? Segundo Skinner, há duas perspectivas: a primeira, a de atentar para o elemento basilar em que o comentador se apoia, mas sem se restringir a ele, que é o texto do autor como chave de compreensão; a segunda é ter especial 
atenção para as estratégias que cada autor utiliza para disfarçar ou mascarar certos temas dentro de suas doutrinas. Seja num caso, seja no outro, o fato é que o comentador está sujeito a esses erros metodológicos e, por isso mesmo, texto do autor tem que ser a referência.

Feitas as análises das duas abordagens, que têm sérios limites, Skinner defende seu próprio método. Para ele, boa parte dos erros dos comentadores da história da Filosofia Política está em não apresentar, primeiramente, um método historiográfico consistente e, em segundo lugar, em não analisar o sentido de um texto dentro de seu contexto linguístico.

O fundamento da tese central de Skinner é que os homens não só dizem as coisas, mas as fazem a partir do que é dito. Isso significa dizer que o falar tem uma boa relação com o fazer. Essa tese, que no fundo está em Wittgenstein, quando este se pergunta sobre a passagem do discurso à ação: "palavras também são atos" (WITTGENSTEIN, 1958, p. 146), e que Skinner a mobiliza com a teoria dos atos de fala (speach as theory) de Austin.

John Austin publicou uma série de conferências em 1955, intitulada How to do things wich words. Para ele, a elucidação de um enunciado não é suficiente para a sua compreensão, porque é preciso reconstituir não o que se diz, mas o que se faz com o que se diz. Tais enunciados são definidos como "performativos", justamente para indicar que "a emissão de um enunciado é a efetuação de uma ação" (AUSTIN, 1975, p. 6). Isso ele denomina "ilocucionário", e Skinner chamará de intenção. Então, vale dizer que todo enunciado tem um sentido (meaning), mas a sua compreensão (understanding) supõe uma intenção. Os atos da fala correspondem ao que se compreende hoje por sentido ou significação, já os atos da ação dizem alguma coisa por si só. Então, para Skinner, a compreensão de um sentido dado depende da existência de procedimentos convencionais ou do contexto linguístico ali produzido. Por essa razão, ainda para esse autor, a tarefa do historiador consiste em descobrir a intenção do autor por trás dos textos. Cabe a ele, o historiador, delimitar os enunciados do autor e estabelecer uma relação entre eles e o contexto linguístico. Na busca pelas intenções do autor, é preciso evitar o subjetivismo e concentrar atenção naquilo que está escrito e acessível a todos, como afirma Skinner,

De modo a recuperar tais intenções, é normalmente tido como essencial cercar o texto dado com o contexto apropriado de pressuposições e convenções a partir do qual o significado exato intencionado pelo autor pode ser decodificado. Isto acarreta a conclusão crucial de que o conhecimento das pressuposições e convenções deve ser essencial para a compreensão do significado do texto. (SKINNER, 1975, p. 216). 
Skinner, então, parte do pressuposto de que é possível reconstituir as intenções do autor graças às convenções linguísticas, porque, quando escreveu ou publicou o seu texto, o autor não pôde fazê-lo fora dos padrões de comunicação de sua época. Isso conduz o historiador a mobilizar um quadro argumentativo de símbolos e de representações constitutivas da época, para que possa reconstituir a intenção do autor. Skinner fornece um contra exemplo, o de como não se deve fazer, que é a leitura de Macpherson sobre Locke. O comentador canadense, que faz uma análise marxista do pensador inglês, defende a ideia de que Locke teria sido o defensor da acumulação ilimitada do capital em pleno século XVII. Ora, para essa interpretação, seria preciso que Macpherson provasse que a sociedade na qual vivia o autor inglês se preocupasse com a acumulação ilimitada de capital por força de um critério, de uma ideologia vigente. Seria preciso, ainda, que Locke revelasse isso em seu próprio texto, o que não foi o caso. Foi em vista disso, decerto, que Macpherson, após sua obra, teria sido tão criticado por, praticamente, todos os comentadores de Locke.

Namazi, interpretando Skinner, resume o procedimento do historiador inglês:

Para que o leitor possa compreender a intenção do autor, este último deve transmitir sua intenção pelas convenções existentes e aceitas pelos leitores. $\mathrm{O}$ historiador não deve limitar sua pesquisa ao texto do autor; ele deve levar em conta as convenções que prevalecem para o tratamento dos temas abordados pelo texto, as crenças do meio do autor, e seu mundo mental. (NAMAZI, 2014, p. 23).

Esse procedimento permite ao historiador conhecer não propriamente o que o autor do passado disse, mas o que os enunciados significam em relação ao contexto e à rede de crenças em que seu pensamento se insere. Com isso, Skinner desloca a atenção do comentador do texto da obra para seu contexto e para o autor inserido nesse contexto. É esse movimento do autor para com o contexto linguístico que Skinner tanto reivindica nas pesquisas em Filosofia Política.

Skinner, na condição de quem melhor sistematizou filosoficamente os pontos essenciais da "Escola", foi também quem mais recebeu críticas ${ }^{4}$. Do ponto de vista da Filosofia, as questões mais recorrentes nessas críticas giram em torno do que viria a ser compreendido por "contexto" e o que significaria "intenção do autor". Se para uma visão tradicional, o texto é determinado pelo contexto histórico (é só lembrar a tese sobre a qual Peter Laslett se tornou célebre), o método proposto por Skinner não acrescenta muito à Filosofia Política, razão pela qual ela seria sem sentido e, portanto, inútil.

\footnotetext{
${ }^{4}$ Para maiores detalhes sobre esse debate do ponto de vista mais sociológico, ver Silva (2010).
} 
Nesse sentido, se a leitura do texto por si só é limitada, a do contexto aprisiona o comentador ao próprio contexto. A pergunta que vários críticos de Skinner fazem, inclusive Namazi, é praticamente a mesma: se, para a compreensão do pensamento de determinado clássico, for necessária a reconstrução dos enunciados dispersos na obra estudada, como se deve proceder com autores que não apresentam doutrina sistemática? Como proceder em casos cujos autores não têm sistematicidade e, além disso, não fornecem todos os elementos de sua doutrina ao leitor, exigindo deste, portanto, maior reflexão e atenção? A ausência de explicações mais profundas sobre esse ponto fez com que Skinner recebesse críticas ainda mais contundentes (NAMAZI, 2014, p. 14). Ora, Namazi sistematiza quatro críticas fundamentais, do ponto de vista filosófico, ao método de Skinner.

A primeira delas, é que o inglês dá muito mais importância aos enunciados do que ao próprio texto de um autor, razão pela qual o seu método não ajudaria a própria Filosofia. A tônica dada aos enunciados dispersos no tempo, no espaço e em suas circunstâncias, em detrimento de uma obra, pode ter justamente efeito contrário ao desejado, o de privilegiar aspectos secundários no lugar dos essenciais. Além do mais, o sentido de "intenção", usado por Austin, quando aplicado à Filosofia, pode ter outra conotação, tornando-se de pouca utilidade para a Filosofia Política.

A segunda é que a análise do contexto linguístico pode limitar muito a compreensão do próprio texto, no lugar de ampliá-la. Isso porque o método não dá muito espaço para a inovação ou ideias cujos filósofos romperam com sua época. Com dose de ironia, afirma Namazi:

\footnotetext{
Não há nada mais espantoso se um grande filósofo fala de tal maneira que escapa a seus contemporâneos. De fato, os que nós consideramos como pensadores revolucionários transformaram a linguagem corrente de suas sociedades. (NAMAZI, 2014, p. 25).
}

A terceira crítica repousa no fato de que Skinner defende a ideia segundo a qual apenas no contexto se pode compreender a intenção do autor, conforme foi registrado acima. Ora, rebate Namazi, os grandes filósofos se tornaram notáveis justamente porque foram capazes de ultrapassar a barreira do tempo com seus legados, os textos. Posto que eles se referem à ideia, ou seja, à natureza humana, o contexto histórico perde seu grau de importância. E questiona o crítico: "Se os filósofos que nos interessam só se interessassem aos problemas de seus contextos, por que deveríamos lê-los apenas como interlocutores num debate historicamente dado?” (NAMAZI, 2014, p. 25). 
A quarta e última crítica é o fato de Skinner vincular, necessariamente, o autor ao contexto. Ora, nada impede que um pensador possa escrever num momento e ser lido e útil em outro, em época completamente diferente. Como afirma Namazi:

\begin{abstract}
Eles escreveram para homens como nós, com as mesmas características físicas e psicológicas; esses homens tinham os mesmos desejos corporais e psíquicos que nós, isso porque eles eram homens, apesar de tudo e de todas as diferenças, sem dúvida, importantes. [...] nós vemos que eles pensaram as mesmas coisas que nós, a justiça, a natureza humana, a autoridade, a igualdade, o amor, a guerra, os deuses e a sua tarefa diante da vida humana. (NAMAZI, 2014, p. 27).
\end{abstract}

Enfim, o método de Skinner defende a ideia de que cabe ao historiador a tarefa de reconstrução de um contexto intelectual, considerando todas as dificuldades inerentes, notadamente, a de ler centenas de obras (quando for o caso), a tradição crítica, os panfletos, cartas, discursos, jornais, polêmicas e debates do período, e todo e qualquer texto vinculado ao contexto linguístico da época. Ora, essa tarefa parece insana, considerando-se os vários limites para o pesquisador: tempo, espaço, delimitação do objeto da pesquisa, de condições materiais e econômicas para encontrar e reunir os textos necessários para a empreitada. Essas exigências, para além das possibilidades do historiador, por mais sério que seja, conduz Namazi, mais uma vez, a uma dura crítica a Skinner. Afirma ele:

\begin{abstract}
Skinner se vê como historiador, um homem de ciência que pretende fundar princípios científicos de sua disciplina. Sua visão é moderna, e ele leva a história ao pé da letra. Ele está em busca da verdade histórica, do que se passou verdadeiramente, ele quer conhecer, com certidão, a opinião de um homem do século XVII. Só podemos admirar sua devoção científica. (NAMAZI, 2014, p. 29, grifos do autor).
\end{abstract}

Ainda na década de 1960 do século passado, surgiu na França uma espécie de movimento que dava relevo ao texto e via a impossibilidade da recuperação do significado original do texto, especialmente o pretendido pelo autor. É conhecida a frase segundo a qual “não há nada fora do texto", defendida por Derrida (1967, p. 227) e assumida por Barthes (1969) e por Foucault (1969), que adotaram a expressão “morte do autor” como princípio básico na compreensão de um texto. Porém, foi Paul Ricoeur quem melhor pontuou as críticas a Skinner, ainda no final da década de 70 do século passado:

Com o discurso escrito, a intenção do autor e o significado do texto cessam de coincidir. Esta dissociação entre o significado verbal do texto e a intenção mental é o que está realmente em questão na inscrição do discurso. Não que possamos conceber um texto sem um autor; a ligação entre o autor e o discurso não é abolida, mas distendida e complicada. [...] a carreira do texto escapa ao finito horizonte vivido por seu autor (RICOEUR, 1979, p. 78).

Sapere aude - Belo Horizonte, v. 8, n. 16, p. 469-491, ago./dez. 2017 - ISSN: 2177-6342 
Isso significa dizer que Skinner não percebe que o texto pode provocar nos leitores ações e lutas, graças ao conteúdo dos enunciados do texto, fonte primária, sem necessariamente recorrer a uma gama de elementos outros do contexto.

No Brasil, um dos pioneiros em utilizar elementos da metodologia de Skinner talvez tenha sido Renato Janine Ribeiro, que, em 1984, defendeu sua tese na USP, intitulada Ao leitor sem medo: Hobbes escrevendo contra seu tempo. Em 1985, Ribeiro publicou um artigo ${ }^{5}$ em que explicou a abordagem adotada em sua tese sobre Hobbes, que logo passou a ser uma referência metodológica para as pesquisas nas áreas de Ética e Filosofia Política no país ${ }^{6}$.

Ribeiro parte do pressuposto de que o texto de um filósofo político não pode ser lido sem as tensões que lhe são próprias, sendo uma das mais notáveis seu destinatário, ao que, segundo ele, Skinner não dá importância. Seu ponto de partida é o texto, como Skinner, mas critica aqueles que reduzem a leitura ao contexto, sobretudo historiadores e cientistas sociais. Isso ocorre, segundo ele, porque, muitas vezes, essas áreas do conhecimento concebem o pensamento político como estanque, estagnado no período histórico em que foi produzido, cabendo ao intérprete a tarefa de aproximá-los (no caso, o texto e a época de sua produção). Ora, nessa tentativa de juntar pensamento, de um lado, e ação, do outro, o comentador prende o autor, por assim dizer, a uma teoria, a uma doutrina, a uma classe social ou mesmo a uma facção política, simplificando e restringindo o pensamento do autor estudado a uma só perspectiva, pondo o leitor como que numa camisa de força. Como Skinner, o professor da USP dá um exemplo de leitura feita por Machpherson do pensamento político de Hobbes: "Hobbes defendia o poder absoluto dos reis [era, portanto, realista] com base no contrato e não no direito divino (quer dizer, em valores burgueses e não monárquicos” (RIBEIRO, 1999, p. 343).

Embora Ribeiro não aprofunde seu viés metodológico ou assuma sua vinculação estreita ao de Skinner, veem-se alguns elementos e que ele sintetiza em alguns pontos fundamentais:

\footnotetext{
${ }^{5}$ Esse mesmo artigo de Ribeiro (1985) foi republicado, sem grandes alterações da parte do autor, como anexo na segunda edição de Ao leitor sem medo: Hobbes escrevendo contra seu tempo (1999, p. 340-352). Fazemos uso dessa última edição.

${ }^{6}$ Essa discussão parece que está mais avançada em outras áreas, como na História e nas Ciências Sociais. Sobre esse debate, ver Vanli e Goulart (2014), Lopes (2011), Silva (2010) e Feres Junior (2005).
} 
1) o pesquisador, na área de Ética e Filosofia Política, deve sempre partir do texto, e não do contexto (a leitura que parte do contexto conduz o leitor ao enquadramento, à simplificação do pensamento do autor);

2) ao longo da leitura, todas as ligações possíveis devem ser observadas e testadas (metáforas, figuras de linguagem, proveniências teóricas e argumentos do autor);

3) a quem o autor se dirige (lapsos e atos falhos do autor viram pistas para a sua melhor compreensão).

Sobre esse ponto, nas palavras de Ribeiro:

Um texto não é uma reflexão, porém, arma. Um pensador político não procura refletir o seu tempo e sociedade; quer produzir efeitos. E estes ele visa através de sua arma específica, o texto. Os leitores constituem o campo de eficácia própria do discurso. A leitura é o processo pelo qual se dá tal eficácia. Escrever e ler, portanto, não são meros efeitos: são produzires. (RIBEIRO, 1999, p. 347).

Assim, ao ler um filósofo político é preciso fazer recortes na obra de tal forma que se detectem os interlocutores de seu autor: quem é escolhido e quem é excluído do diálogo; quais seriam também as omissões, as repetições, as filiações pessoais ou imaginárias. Descobrir esses aspectos em um texto se torna essencial, para Ribeiro, porque o texto comentado fornece elementos necessários à compreensão das inter-relações estabelecidas, na obra estudada, com o leitor.

\section{II}

O pensamento político de Locke foi interpretado nos últimos três séculos de formas bem distintas e, por vezes, de maneira paradoxal: há uma leitura liberal tanto quanto uma marxista; há uma que defende sua secularização e há outra que sustenta sua veia teológica. Isso demonstra sua diversidade, riqueza teórica e vitalidade. Assim, o objetivo desta parte do texto é reconstituir o debate interpretativo sobre o pensamento político de Locke, visando-se entender seus principais argumentos e características no tempo e no espaço. Este quadro, ainda que panorâmico, pode ajudar o leitor a melhor compreender a tradição crítica voltada ao pensador inglês, ao menos as interpretações tidas como clássicas. Podem-se sistematizar as 
tradições interpretativas do pensamento de Locke em três momentos históricos diferentes: a tradição liberal, a marxista e a "Escola de Cambridge"". Isso porque, como afirma Goldie:

Locke falou a diferentes públicos, de diferentes maneiras, modulou seus pensamentos de acordo com as circunstâncias, exprimiu o que era adequado dentro da dinâmica de disputas particulares, e colaborou com colegas ao formular 'suas' ideias. (GOLDIE, 2007, p. XLV).

Uma das primeiras interpretações do pensamento lockeano ficou conhecida como “tradição liberal”. Ela engloba, grosso modo, duas fases distintas: num primeiro momento, ganha terreno a ideia de que os valores defendidos por Locke, como a igualdade e a liberdade natural, serviram para ideologia oficial do Whig Party, do século XVII até o século seguinte; num segundo momento, a leitura do Locke passou a ser associada à de Hobbes, especialmente quanto às premissas individualistas, já no final do século XIX e início do XX.

No que concerne à primeira leitura, ela toma como ponto de partida a velha ideia de que Locke "foi o fundador do liberalismo" o que serviu, em larga medida, como recurso de propaganda política na era vitoriana. Ela apresenta dois pilares: o primeiro, a ideia de que o pensamento político de Locke tem uma base utilitarista; o segundo, a ideia de que sua obra teria servido como "bíblia política" no século XVIII. No primeiro caso, está em jogo o conceito mesmo de virtude, que conduz à felicidade e à sua teoria moral, que oscila entre sua fé racionalista e uma ética de base utilitarista. No segundo, está em jogo a compreensão de sua teoria da sociedade civil. O marco dessa interpretação foi a obra de Leslie Stephen, intitulada English Thougt in the Eighteenth Century, publicada em Londres, em 1876 (reeditada em 1991, em dois volumes). Para Spitz (1994, p. XLI), essa interpretação acusa Locke de incoerente, posto que, se de um lado sua teoria moral e política é utilitarista, por outro lado o pano de fundo de seu pensamento é "metafísico", "inatingível", "impraticável".

No que diz respeito à segunda fase de interpretação de Locke, ainda na tradição liberal, ela foi marcada pela leitura de Laski, que defende a ideia de seu pensamento político segundo a qual a existência humana seria inteiramente secularizada e o Estado seria

\footnotetext{
${ }^{7}$ Essa tentativa de sistematização das diferentes interpretações de Locke nessas três tradições pode ocorrer em algumas exceções que fogem ao esquema. No entanto, nada impede de pensar sobre a obra de Locke por intérprete, fugindo assim às escolas interpretativas. $\mathrm{O}$ fato é que Locke foi lido por seus próprios contemporâneos como "o fundador da Filosofia das Luzes", tais como Collins, Molyneux, Shute, mas também pelos franceses, como Jean Leclerc, Voltaire e Condorcet. Ver Viano (1960) e Dunn (1991, p. 15, 21). Leo Strauss (1953) vê Locke de uma forma enigmática e conservadora, com base na lei natural. Willmoore Kendall (1941) entende Locke como o teórico constitucionalista por excelência, que vê no poder da maioria a fonte da autoridade política. Não se pode esquecer também os trabalhos bem-sucedidos de Yolton (1969), Polin (1960), Michaud (1991), Spitz (2001), Namazi (2014), Sousa (2017).
} 
mecanicista e instrumental, dedicado à proteção dos desejos individuais. Essa tese básica vai somar-se a outras, na mesma esteira da leitura de Hobbes como defensor das ideias liberais, havendo um Estado forte para proteger os indivíduos contra os excessos das paixões violentas e egoístas do homem. Essa leitura, além de aproximar os dois ingleses do século XVII, sem distinguir as diferenças entre eles, põe uma sobreposição de Hobbes a Locke, na medida em que entende a figura do Estado como proteção e fundamento da obrigação do interesse individual. Embora essa leitura esteja cheia de equívocos, ela permitiu críticas e expansão do debate sobre a relação entre os dois ingleses e suas especificidades no século seguinte (LASKI, 1920).

A segunda tradição interpretativa, que predominou do final do século XIX ao início do século XX, foi a marxista. A especificidade desse tipo de leitura é que ela relaciona os Dois tratados e os escritos políticos e econômicos no contexto das duas revoluções inglesas, visando a tomada da consciência de classe para o reconhecimento de direitos políticos, econômicos e sociais. Ao relacionar o pensamento político com o econômico de Locke, Marx e Engels puseram à luz o fundamento filosófico do pensamento político e de sua obra econômica, que começou na Sagrada família, capitulo VI e estendeu-se às referências na Ideologia alemã, na Contribuição à economia política e no Capital.

Apesar de Locke aparecer nessas obras como o defensor da classe dos proprietários dos meios de produção, para Marx sua contribuição para a Economia Política é inegável, graças à sua definição de valor de uso, de suas pesquisas sobre juros, moeda, relação entre economia e pobreza, dentre outras, o que faz do inglês o "patrono da economia política moderna” (MARX, 1975, L, 1, p. 751). Todavia, talvez, nada chamou tanto a atenção de Marx, na obra de Locke, do que o capítulo V do Segundo tratado, justamente o que diz respeito à propriedade. As referências do alemão ao inglês vão ajudar a divulgação de uma ideia de que a obra máxima de Locke seria portadora de ideias socialistas, mesmo tendo saído das raízes do liberalismo econômico e político, por mais paradoxal que possa parecer.

Nessa perspectiva, uma das leituras mais marcantes dessa tradição foi a de Machpherson (2004). Para esse canadense, Locke é o representante e teórico máximo da classe burguesa, que defende a propriedade privada e a exploração do trabalho como forma de garantir a existência da classe trabalhadora. Para o intérprete, a teoria de Locke sobre o direito natural está fundada na desigualdade dos direitos naturais individuais e, enquanto tal, visa a exclusão das classes trabalhadoras da comunidade moral e política. Para o canadense, todo o arcabouço do capitalismo nascente está presente na obra do inglês: acumulação do capital, 
transformação da terra e do trabalho em mercadoria, instauração do Estado para proteger os interesses dos proprietários e, por outro lado, de um individualismo crescente sem os meios de produção. Apesar de apresentar uma interpretação anacrônica, mas válida e legítima para aquela época, ela suscitou enorme debate entre os pesquisadores da política moderna.

A terceira tradição interpretativa de Locke é a da "Escola de Cambridge", cujos eixos centrais foram analisados na primeira parte deste texto. Ao que tudo indica, houve quatro razões que possibilitaram a renovação da pesquisa sobre Locke na segunda parte do século passado, de modo particular, vinculado a essa Escola.

A primeira delas foi que, até 1947, muitos manuscritos, diários, cartas e esboços das obras de Locke, que se acreditava perdidas, foram encontradas, catalogadas e enviadas para a Bodleian Library, em Oxford, de tal modo que somente nos últimos cinquenta anos foi possível o acesso a essa documentação (LONG, 1959). Esses textos também deram luz a uma antiga discussão, notadamente de Strauss, a de que Locke teria uma escrita exotérica e dissimulada. Os documentos encontrados apontam para a similaridade entre os manuscritos e os publicados, de tal modo que cai por terra eventual dissimulação da sua escrita, conforme prega o professor da Escola de Chicago.

A segunda razão diz respeito diretamente às pesquisas de Peter Laslett, conforme apresentadas na primeira parte deste texto. Para esse professor, Locke escreveu sua obra política máxima no contexto da "Crise de exclusão". Trata-se de uma crise política, ocorrida entre 1678 e 1681, sob o reinado de Carlos II. Grosso modo, ela diz respeito à exclusão do irmão de Carlos II, o futuro rei James II, da sucessão do trono da Inglaterra, em função de seu vínculo com a Igreja Católica. Ora, por que isso seria perigoso para a Inglaterra naquele momento? Um rei católico, num país anglicano, poderia restaurar sua religião, pondo-a no lugar da oficial, traindo, assim, seu povo e a palavra dada. Seria ele, então, uma ameaça aos direitos adquiridos, que poderiam ser questionados a ponto de atingir os bens, a liberdade e a própria vida do povo inglês. Haveria, portanto, a necessidade de todo o esforço possível para evitar tamanhas rupturas políticas. Para Laslett, é nesse momento que, incentivado por Shaftesbury, Locke teria escrito o seu livro, e não em 1689, para justificar a ascensão ao trono de um novo monarca. Como registra Ashcraft (1995, p. 85),

os 25 anos que separam a saída de Oxford da publicação dos Ensaios, vibram de excitação, de intrigas e de perigos na vida política. Locke passa alguns desses anos assumindo funções oficiais, mas, na maior parte, são anos de oposição política ao governo, de reuniões secretas, vividos com um falso nome e sob uma falsa identidade; anos de clandestinidade, de exílio, de conspiração e de revolução. 
Em terceiro lugar, a profusão de publicações, após a edição do Segundo tratado feita por Laslett, provocou uma espécie de guinada metodológica nas pesquisas sobre Locke, enriquecendo largamente o debate. Esse fato marcou significativamente seja o conteúdo do pensamento do autor inglês seja a forma de lê-lo. Num ponto, todos os intérpretes estão de acordo: podem-se fazer várias críticas ao Skinner e a sua "Escola", mas nenhum pesquisador sério pode ler Locke sem considerá-la e sem situar Locke historicamente para melhor compreendê-lo. Foi graças à essa "Escola", com suas críticas, embates e debates, que se ampliou o foco de discussão sobre o pensamento político de Locke. Como afirma Dunn:

Skinner considera que a historicidade dos textos é fundamental e os apreende, em última análise, como ações humanas extremamente complexas. Ela põe relevo especialmente sobre a tarefa determinante da intenção da organização humana recusando sempre em reduzir as ações humanas a suas intenções conscientes. (DUNN, 1992, p. 21).

Em quarto lugar, ainda nas razões que possibilitaram uma reavaliação das pesquisas sobre Locke e, consequentemente, a formação da "Escola de Cambrigde", foi a interpretação de Pocock (1989) baseada na linguagem política. Para esse intérprete, a linguagem tinha importância decisiva para a estruturação do debate, no período da redação e publicação dos Tratados de Locke. Essa ideia, que se somou à tendência da "Escola" em formação na época, foi decisiva para fortalecer uma maneira de pesquisar Locke situando-o historicamente, a partir da linguagem política em uso no contexto dos acontecimentos na Inglaterra daquele período. Por essa razão, Pocock vai analisar a antiga Constituição inglesa, para saber os termos do debate político naquele momento, em que se envolviam os partidários dos Stuarts e os adversários da monarquia absoluta, na tentativa de entender os termos da controvérsia e o contexto da "Crise da exclusão" que se estendeu até depois da Revolução Gloriosa (POCOCK, 1988). Na sequência dos acontecimentos, afirma Spitz,

Todo o mundo sabe que, após a Revolução, o compromisso entre whigs e tories foi sobre base, talvez, conservadora: nenhum retorno à anarquia, o governo não foi dissolvido, as instituições foram mantidas e tratou-se simplesmente da vacância do trono da parte de Jacques II que o abandonou voluntariamente, e não sob a pressão da resistência do povo. (SPITZ, 1994, p. LXI).

Isso leva o leitor a crer, reforçando a tese de Laslett, que a teoria de Locke não foi pensada para dar suporte oficial à Revolução Gloriosa, razão pela qual ela não teria tido nenhum efeito prático. De qualquer modo, e isso talvez seja o mais importante na leitura de Pocock, é que existiu sim uma linguagem pública e organizada naquela época, que permitiu o 
debate sobre a situação política inglesa, o que promoveu um aprimoramento da sociedade e dos costumes políticos.

Dentro da "Escola" inglesa, há duas leituras recentes que se destacaram pela ousadia na análise: a de John Dunn e a de Ricahrd Ashcraft.

Um dos aspectos mais fortes da tese de Dunn é que ele desafia aqueles que pretendem ler o pensamento político de Locke desconsiderando seu aspecto teológico. Segundo esse intérprete, Locke tem um axioma que perpassa todo o seu pensamento: há um Deus que dá aos homens regras básicas para bem viver (DUNN, 1991, p. 21). Retirando-se esse axioma de seu pensamento, toda a sua estrutura corre o risco de desabar. Isso porque, ainda para o comentador, a base teológica que permeia o pensamento lockiano é calvinista, não somente na teoria, mas também na prática: Locke foi um devoto inveterado. Esse aspecto ganha relevância na leitura de Dunn porque para Locke o homem, enquanto criatura divina, é chamado a cumprir sua vocação no mundo, e essa tarefa passa pela ideia de dever e da lei natural, inseparáveis da lei divina, fundamentos de sua obrigação moral. Como afirma Dunn (1991, p. 223)

Todos os homens têm uma vocação [...] A palavra-chave da teoria da vocação no pensamento puritano é a mesma na sua reformulação em Locke: um igualitarismo cristão, uma igualdade que se revela na submissão de todos os homens às exigências das mais desafiadoras para a sua realização. (DUNN, 1991, p. 223).

Assim, nessa leitura, graças ao trabalho do homem, a primeira lei natural está garantida: a preservação de si próprio. Entretanto, essa preservação é acompanhada de deveres, individuais e sociais, porque a vida nada mais é do que um instrumento da Graça, para a realização dos designíos de Deus e conter os meios necessários para que o homem, eventualmente, não se afaste Dele. Isso significa dizer que...

Deus, que é o garantidor desta ordem dos valores, é também a chave epistemológica de sua compreensão. [...] Neste quadro de uma tal ética, o julgamento moral aparece claramente como uma questão de ordem cognitiva (DUNN, 1991, p. 34-35).

Nesse sentido, não pode haver humanidade fora do contexto religioso, porque o homem depende de seu criador, que continua agindo na sua criação por meio da Graça, para que a criatura possa desenvolver sua vocação tal qual Deus quis por meio da lei natural, sob a capa da razão. O próprio estado de natureza, para Locke, longe de ser um lugar em que impera a guerra, é um espaço que tem lei, igualdade, racionalidade e autoridade divina, graças à lei de natureza. 
A leitura de Richard Ashcraft, sobre o pensamento político de Locke, analisa o radicalismo político que se estabeleceu na Inglaterra, entre os anos de 1670 e 1680, do qual Locke foi grande expoente. Para ele, a obra Segundo tratado sobre o governo foi o maior manifesto político desse movimento. Segundo esse intérprete, há uma tradição de leitura da obra máxima de Locke como se ela fosse absolutamente teórica, sem vínculo com a ação política do momento vivido pelo pensador inglês. Ora, a tarefa desse comentador é analisar a obra no contexto da "Crise de exclusão" e demonstrar que houve uma resistência armada e radical, contra os Stuarts, razão pela qual Locke mobilizaria os conceitos fundamentais de seu pensamento político, para resistir à força ilegítima. Isso significa dizer que, para essa leitura, a maior obra política de Locke não pode ser lida como um livro de Filosofia, mas como um documento panfletário, destinado à promoção das ideias whig, incentivadas por Shaftesbury ${ }^{8}$.

Enfim, para a "Escola de Cambridge", não se deve analisar a história política a partir de conceitos, porque eles mudam ao longo do tempo, tomando novos contornos e feições, mas a partir de usos discursivos dos conceitos em ocorrências específicas. Nessa perspectiva, não haveria a história do conceito "liberdade", mas uma história dos usos do termo liberdade, elaborada por pensadores, em um contexto específico. Assim, às perguntas sobre o que é justiça, liberdade, corrupção, tolerância etc., típicas da Filosofia Política, mesmo que as respostas dadas em determinada época não sirvam à atualidade, permanecem válidas, pelo menos, como questões fundamentais. Elas ajudam o leitor contemporâneo a melhor entender os problemas que o atingem diretamente. Essas questões, por um lado, suscitam os eventuais erros do passado e projetam, por outro lado, as condições mais favoráveis ao futuro.

É evidente que não há conceitos eternos e imutáveis, porque todos eles foram forjados num tempo e num espaço específicos. Porém, é possível aprender com os textos do passado, "porque toda obra da filosofia política é uma intervenção no debate, uma resposta aos argumentos ali propostos" (SPITZ, 1994, p. VIII) e, enquanto tal, servem para enriquecer a percepção e a discussão dos problemas semelhantes no mundo atual. Sendo assim, a Filosofia Política é mais atual do que nunca, e a prova disso é sua vitalidade no pensar as questões contemporâneas. É certo que cada época lê diferentemente os mesmos problemas abordados por um autor. Por isso, cabe considerar que o próprio autor e sua temática, com sua maturidade e seu pensamento sobre as inquietações de seu tempo, ajuda a pensar as atuais e,

\footnotetext{
${ }^{8}$ Essa perspectiva de leitura está em conformidade com a metodologia da "Escola" inglesa, segundo registra o próprio autor: "É sempre pertinente, quando se interessa na interpretação de uma teoria política dada, destacar problemas que podem ser relacionados ao universo social do autor, à natureza do público visado e aos objetivos em vista dos quais esta teoria foi anunciada" (ASHCRAFT, 1995, p. 4).
} 
por isso, não há exagero em dizer que Locke contribui imensamente na construção dos conceitos da política moderna, com fortes ecos, portanto, no mundo contemporâneo.

Essas leituras, que formaram verdadeiras tradições interpretativas, apesar das diferenças entre elas, seja de época, seja de foco, apontam para o aspecto da modernidade do pensamento lockiano: sua religiosidade e ao mesmo tempo seu distanciamento da religião, a noção de direito subjetivo anterior ao dever, a noção de indivíduo que busca segurança e prazer em meio a uma sociedade civil, formada de homens políticos e sociais. Tudo isso fez de Locke ora o pensador liberal ora crítico do próprio liberalismo, tendo um papel central e por demais fecundo no pensamento político desde o início da Modernidade até a atualidade, sempre provocando novas interpretações.

\section{REFERÊNCIAS}

ASHCRAFT, Richard Coll. La politique révolutionnaire et Les deux traités du gouvernement de John Locke. Paris: PUF, 1995.

AUSTIN, John Langdon. How to do things with words (2nd ed.). Cambridge, Massachusetts: Harvard University Press, 1975.

BARTHES, Roland. (1968). La mort de l'auteur. Manteia, Marseille, vol. 5, no 4, p. 12-17.

BLOOM, Allan. Leo Strauss. In: BLOOM, Allan. Gigantes e anões. São Paulo: Best Seller, s.d.

BOBBIO, Norberto. Razões da filosofia política. In: BOBBIO, Norberto. Teoria geral da Política: a Filosofia Política e as lições dos clássicos. Rio de Janeiro: Campus, 2000.

CRANSTON, Maurice. John Locke: A biography. New York: Macmillan, 1957.

DERRIDA, Jacques. De la Grammatologie. Paris: Minuit, 1967.

DUNN, John. The identity of the history of idea. Philosophy, vol. XLIII, n. 134, p. 85-104, 1968.

DUNN, John. Histoire de La théorie politique. Paris: Édition Mentha, 1992.

DUNN, John. La Pensée Politique de John Locke. Traduction. Jean François Baillon. Paris: PUF, 1991.

FERES JUNIOR, J. De Cambridge para o mundo, historicamente: revendo a contribuição metodológica de Quentin Skinner. DADOS: Revista de Ciências Sociais, Rio de Janeiro, Vol. 48, no 3, p. 655-680, 2005. 
FOUCAULT, Michel. Qu'est-ce qu'un auteur. Bulletin de la Société Française de Philosophie, vol. LXIV, Paris, 1969.

GADAMER, Hans-Georg. Verdade e Método I (6a ed.). Petrópolis/Bragança Paulista: Vozes/Editora da Universidade São Francisco, 2004.

LOCKE. John. Questions concerning the law of nature. NY: Cornell University Press, 2008.

LASKI, H. Political thought. In: LASKI, H. England from Locke to Bentham. Londres: Echo 1920.

LASLETT, Peter. Philosophy, politics and society. Oxford: Blackwell, 1956.

LASLETT, Peter. Patriarchalism in seventeenth hinking. Filmer and his Contemporaries. In: FILMER, Robert. Patriarcha and Other Political Works. Oxford: Basil Blackwell, 1949.

LASLETT, Peter. Introduction. In: LOCKE, John. Two treatises on government. Cambridge: Cambridge University Press, 1960.

LASLETT, Peter. Apresentação. In: LOCKE, John. Dois tratados sobre o governo. São Paulo: Martins Fontes, 2001.

LONG, P. A summary catalogue of the Lovelace Collection of the papers of John Locke in the Bodleian Library. Oxford: Oxford University Press, 1959.

LOPES, M. A. Aspectos teóricos do pensamento histórico de Quentin Skinner. Kriterion, Belo Horizonte, n. 123, Jun, 2011.

MACPHERSON, C. B. La théorie politique de l'individualisme possessif: de Hobbes à Locke. Traduction Michel Fuchs. Paris: Gallimard-Folio, 2004.

MARX, K. Le capital. Paris: 1975.

MARX, Karl; ENGELS, Friederic. La Sainte famille ou critique de la critique contre Bruno Bauer. Paris: Cogniot, Ed. Sociales, 1972.

NAMAZI, R. Le problème théologico-politique de John Locke. Paris: Thèse de l'École des Hautes Études en Sciences Sociales, 2014.

MICHAUD, Y. Locke. Rio de Janeiro: Jorge Zahar, 1991.

POCOCK, John. Linguagens do ideário político. São Paulo: Edusp, 2003.

POCOCK, John. The History of Political Thought: a methodological enquiry. In: P. Laslett e W. G. Runciman (eds.), Philosophy, Politics and Society (second series). Oxford, Blackwell, p. 183-202, 1962.

POCOCK, John. Langages and their implications: the transformation of the study of Political Thought, Politics Language and Time. Chicago, 1989. 
POCOCK, John. The Ancient Constitution and the feudal Law. Cambridge: Cambridge, 1988.

POLIN, R. La politique morale de John Locke. Paris: PUF, 1960.

RIBEIRO, R. J. Ao leitor sem medo: Hobbes escrevendo contra seu tempo. Belo Horizonte: UFMG, 1999.

RIBEIRO, Renato J. A Filosofia Política na história. Revista Filosofia Política, São Paulo, n. 2, p. 117-126, 1985.

SILVA, R. O contextualismo linguístico na história do pensamento olítico: Quentin Skinner e o Debate Metodológico Contemporâneo. DADOS: Revista de Ciências Sociais, Rio de Janeiro, vol. 53, n 2, 2010.

SKINNER, Quentin. (1966), The limits of historical explanations. Philosophy, Cambridge, v. 41, p. 199-215, 1966.

SKINNER, Quentin. Meaning and understanding in the history of ideas. History and Theory. Middletown, v. 8, no 3, p. 3-53, 1969.

SKINNER, Quentin. (1975), Hermeneutics and the role of history. New Literary History. Baltimore, v. 8, p. 209-232.

SKINNER, Quentin. As fundações do pensamento político moderno. São Paulo:

Companhia das Letras, 1996.

SKINNER, Quentin. Some problems in the analysis of Political Thought and action. In: TULLY, James. Meaning and Context: Quentin Skinner and his critics. Cambridge: Polity Press/Basil Blackwell, 1988.

SOUSA, R. John Locke e a liberdade republicana. São Paulo: Universidade de São Paulo, 2017.

SPITZ, Jean-Fabien. Quentin Skinner, Revue Française d'Histoire des Idées Politiques. Paris, v. 2, n. 40, p. 347-377, 2014.

SPITZ, Jean-Fabien. Présentation. In: LOCKE, J. Le second traité du gouvernement. Paris: PUF, 1994.

SPITZ, Jean-Fabien. John Locke et les fondements de la liberté moderne. Paris: PUF, 2001.

STRAUSS, Leo. The Political Philosophy of Hobbes. Its basis and its genesis. Chicago: The University of Chicago Press, 1984.

VANALI, A.C.; GOULART, M. H. O que vale é a intenção... Texto, contexto, autor e linguagem na perspectiva de Quentin Skinner. Revista Diálogos Mediterrânicos, Curitiba, n. 7, dez, 2014. 
VIANO, C. A. John Locke: dal razionalismo all'Illuminismo. Turino: Einaudi, 1960.

WITTGENSTEIN, Ludwig. Philosophical Investigations. Oxford: Basil Blackwell, 1958.

YOLTON, J. W. Problems and perspectives. Cambridge: Cambridge University Press, 1969. 